\title{
Primary association of HLA-B51 with Behçet's disease in Ireland
}

\author{
D J Kilmartin, A Finch, R W Acheson
}

\begin{abstract}
Aims/background-While a primary association of HLA-B51 with Behçet's disease (BD) in Japanese and Mediterranean patients supports an immunogenetic predisposition, this link is unclear in north western Europe. This study assessed HLA associations with BD, and HLA-B51 with certain clinical characteristics, in the Republic of Ireland, which has an ethnically homogeneous population.

Methods-HLA-A, HLA-B, and HLA-DR typing was performed in $24 \mathrm{BD}$ patients, conforming to International Study Group criteria, and in blood donors, as controls. Patient records were retrospectively reviewed and patients reassessed clinically. Results-A highly significant HLA-B51 association (corrected exact $p$ value $=$ 0.002 , relative risk $=6.3$ ) with $\mathrm{BD}$ was determined, despite a low B51 prevalence $(25 \%)$ in patients. No other HLA type was associated. There was a significant B51 link with male sex in BD patients but no association with age at first manifestation/ diagnosis, eye involvement, cyclosporin $A$ therapy, or poor visual acuity was determined.

Conclusions-This study supports a HLAB51 immunogenetic predisposition, similar to Japanese patients, in Irish BD in an ethnically homogeneous population in north western Europe. However, owing to a low prevalence of $\mathrm{B} 51$ positivity in $\mathrm{BD}$ patients in Ireland, a multifactorial pathogenesis is suggested.
\end{abstract}

(Br F Ophthalmol 1997;81:649-653)

Institute of

Ophthalmology,

University College

Dublin, Mater

Misericordiae

Hospital, Dublin,

Ireland

D J Kilmartin

$\mathrm{R}$ W Acheson

National Tissue Typing Laboratory, The Blood

Transfusion Service

Board, Dublin, Ireland

A Finch

Correspondence to: Mr D J Kilmartin,

Department of

Ophthalmology, University

of Aberdeen Medical School,

Aberdeen AB9 2ZD.

Accepted for publication 14 May 1997 diagnosis in these patients and HLA-B51 testing is included as a laboratory test in the crite- ria of the Behçet's Disease Research Committee of Japan. ${ }^{15}$

Controversy has arisen with regard to the significance of these observations in north western Europe and the USA. ${ }^{16-22}{ }^{25-28}$ No HLA association was found in either US or British patients. ${ }^{16-22}$ Many of these studies were performed before the HLA-B5 antigen was split into its subtypes, with HLA-B51 being strongly associated and not HLA-B52. ${ }^{6}$ HLA typing is not included in the International Study Group Criteria (ISG) ${ }^{23}$ for diagnosis, which may be more commonly used in Europe.

Findings from studies in the west may be more difficult to interpret as there is a much lower prevalence and hence smaller study group of patients. There are apparent differences in the spectrum of Behçet's disease in different populations ${ }^{3}$ and the strength of the HLA-B51 association, emphasising genetic aetiological factors, and its relation with visual prognosis are unclear in north western Europe.

The aim of this study was to investigate whether an immunogenetic predisposition for Behçet's disease is present in an ethnically homogeneous north west European population, that of the Republic of Ireland, and to assess if any relation with visual prognosis exists.

\section{Materials and methods}

Twenty four patients were recruited from the ophthalmology departments of university teaching hospitals and by referral from requests to ophthalmologists, rheumatologists, dermatologists, and genitourinary physicians throughout the Republic of Ireland. All were required to satisfy the ISG criteria for diagnosis of Behçet's disease. ${ }^{23}$ Hospital charts were reviewed retrospectively and each patient was reassessed by one ophthalmologist (DK) and a blood sample for HLA typing was obtained after informed consent.

HLA typing was carried out by the National Tissue Typing Reference Laboratory of the Blood Transfusion Service Board. HLA-A and HLA-B typing was performed by the standard National Institutes of Health microlymphocytotoxicity method and HLA-DR typing was performed by DNA polymerase chain reaction for both patients and controls. The control group consisted of 96 healthy voluntary blood donors to the Blood Transfusion Service Board, of whom all had HLA-A and HLA-B typing and 84 had HLA-DR typing. Age and sex matched consecutively typed controls were chosen for each patient so that both patient and controls were typed at the same time using 
the same antisera. There is only one blood donor service in the Republic of Ireland which operates nationally with one central tissue typing laboratory allowing voluntary blood donors to be used as representative of the general population. Antigen frequencies were counted by direct counting. Statistical significance between the relative frequencies of antigens in patients and controls was determined by $\chi^{2}$ and Fisher's exact tests with Yates's correction. Exact $\mathrm{p}$ values were corrected to avoid a type I error, as outlined by Meenken et $a l,{ }^{24}$ for, in a sample of 53 informative comparisons, one may expect to observe, by chance alone, two to three 'significant' HLA associations. The correction is performed by multiplying the exact $p$ value with the number of antigen frequencies tested (a factor of 53 in our study). All $p$ values given are two tailed. Significance was evaluated by $0.05>p>0.01$ is significant and $p<0.01$ is highly significant.

Any HLA-B51 association with certain clinical features, such as sex, age at first manifesta- tion of disease, age at diagnosis, the presence of eye involvement, visual acuity worse than $6 / 60$ in an affected eye, and requirement for systemic cyclosporin A therapy, was assessed. First manifestation of disease was defined as the first manifestation of one of the ISG diagnostic criteria (including recurrent mouth ulcers). Age at diagnosis was defined as the age at which the ISG criteria for diagnosis were fulfilled. Statistical association with age was assessed using the Mann-Whitney $U$ test for non-parametric data.

\section{Results}

Of the 24 patients with Behçet's disease, all had HLA-A and HLA-B typing and 21 underwent HLA-DR typing. There were 14 male and 10 female patients. All patients were white and of ethnic native Irish origin. HLA antigen frequencies of patients and controls are given in Table 1. A remarkably significant HLA association in patients with Behçet's disease in the Republic of Ireland was found with HLA-B51

Table 1 HLA antigen frequencies in 24 Irish patients with Behçet's disease

\begin{tabular}{|c|c|c|c|c|c|}
\hline \multirow[b]{3}{*}{ Antigen } & \multicolumn{2}{|l|}{ Antigen frequency } & \multirow[b]{3}{*}{$\chi^{2}$} & \multirow[b]{3}{*}{ Relative risk } & \multirow[b]{3}{*}{ Exact $p$ value } \\
\hline & Patients (\%) & Controls (\%) & & & \\
\hline & $(A, B: n=24, D R: n=21)$ & $(A, B: n=96 D R: n=84)$ & & & \\
\hline A1 & 58.33 & 45.83 & 0.8 & 1.5 & 0.386 \\
\hline A2 & 62.50 & 59.38 & 0.0 & 1.1 & 0.963 \\
\hline A3 & 16.67 & 35.42 & 2.3 & 0.4 & 0.128 \\
\hline A9 & 4.17 & 3.13 & 0.2 & 1.3 & 1.000 \\
\hline A10 & 8.33 & 4.17 & 0.1 & 1.7 & 0.345 \\
\hline A11 & 20.83 & 8.33 & 2.0 & 2.2 & 0.133 \\
\hline A19 & 4.17 & 6.25 & 0.0 & 0.7 & 1.000 \\
\hline A 24 & 0.00 & 14.58 & 2.7 & 0.0 & 0.070 \\
\hline A25 & 0.00 & 3.13 & 0.0 & 0.0 & 1.000 \\
\hline A26 & 0.00 & 2.08 & 0.0 & 0.0 & 1.000 \\
\hline A28 & 4.17 & 3.13 & 0.2 & 1.3 & 1.000 \\
\hline A29 & 8.33 & 7.29 & 0.1 & 1.1 & 1.000 \\
\hline A31 & 4.17 & 1.04 & 0.0 & 2.6 & 0.361 \\
\hline A32 & 4.17 & 6.25 & 0.0 & 0.7 & 1.000 \\
\hline A33 & 4.17 & 0.00 & 0.6 & 5.2 & 0.200 \\
\hline B5 & 0.00 & 3.13 & 0.0 & 0.0 & 1.000 \\
\hline B7 & 20.83 & 37.50 & 7.0 & 3.7 & 0.008 \\
\hline B8 & 37.50 & 52.08 & 1.1 & 0.6 & 0.294 \\
\hline B12 & 4.17 & 0.00 & 0.6 & 5.2 & 0.200 \\
\hline B13 & 0.00 & 1.04 & 0.6 & 0.0 & 1.000 \\
\hline B14 & 16.67 & 10.42 & 0.1 & 1.3 & 0.517 \\
\hline B15 & 0.00 & 2.08 & 0.0 & 0.0 & 1.000 \\
\hline B17 & 8.33 & 1.04 & 1.7 & 3.5 & 0.105 \\
\hline B18 & 0.00 & 2.08 & 0.0 & 0.0 & 1.000 \\
\hline B22 & 0.00 & 1.04 & 0.6 & 0.0 & 1.000 \\
\hline B27 & 4.17 & 6.25 & 0.0 & 1.3 & 0.660 \\
\hline B35 & 4.17 & 4.17 & 0.3 & 1.0 & 1.000 \\
\hline B37 & 0.00 & 5.21 & 0.3 & 0.0 & 0.582 \\
\hline B39 & 4.17 & 3.13 & 0.2 & 1.3 & 1.000 \\
\hline B40 & 8.33 & 4.17 & 0.1 & 1.7 & 0.345 \\
\hline B44 & 50.00 & 34.38 & 1.4 & 1.7 & 0.239 \\
\hline B45 & 0.00 & 1.04 & 0.6 & 0.0 & 1.000 \\
\hline B49 & 0.00 & 1.04 & 0.6 & 0.0 & 1.000 \\
\hline $\mathrm{B} 50$ & 0.00 & 1.04 & 0.6 & 0.0 & 1.000 \\
\hline B51 & 25.00 & 0.00 & 20.3 & 6.3 & 0.00004 \\
\hline B53 & 0.00 & 1.04 & 0.6 & 0.0 & 1.000 \\
\hline B55 & 0.00 & 1.04 & 0.6 & 0.0 & 1.000 \\
\hline B57 & 12.50 & 5.21 & 0.7 & 2.0 & 0.197 \\
\hline B60 & 4.17 & 7.29 & 0.0 & 0.6 & 1.000 \\
\hline B62 & 0.00 & 10.42 & 1.5 & 0.0 & 0.209 \\
\hline DR1 & 23.81 & 13.10 & 0.8 & 1.7 & 0.305 \\
\hline $\mathrm{DR} 2$ & 33.33 & 11.90 & 4.2 & 2.6 & 0.041 \\
\hline DR3 & 38.10 & 47.62 & 0.3 & 0.7 & 0.590 \\
\hline DR4 & 19.05 & 40.48 & 2.5 & 0.4 & 0.116 \\
\hline DR6 & 14.29 & 0.00 & 7.7 & 5.7 & 0.007 \\
\hline DR7 & 28.57 & 32.14 & 0.0 & 0.9 & 0.958 \\
\hline DR8 & 0.00 & 1.19 & 0.6 & 0.0 & 1.000 \\
\hline DR9 & 0.00 & 1.19 & 0.6 & 0.0 & 1.000 \\
\hline DR10 & 0.00 & 2.38 & 0.0 & 0.0 & 1.000 \\
\hline DR11 & 4.76 & 8.33 & 0.0 & 0.6 & 1.000 \\
\hline DR13 & 19.05 & 13.10 & 0.1 & 1.4 & 0.494 \\
\hline DR14 & 9.52 & 5.95 & 0.0 & 1.5 & 0.625 \\
\hline DR15 & 4.76 & 20.24 & 1.9 & 0.2 & 0.114 \\
\hline
\end{tabular}


Table 2 HLA-B51 status and sex in Irish Behçet's disease

\begin{tabular}{lllll}
\hline & & \multicolumn{2}{l}{ HLA-B51 status } \\
\cline { 3 - 4 } Sex & $\begin{array}{l}\text { Total } \\
(n=24)\end{array}$ & $\begin{array}{l}\text { B51 } \\
\text { positive } \\
(n=6)\end{array}$ & $\begin{array}{l}\text { B51 } \\
\text { negative } \\
(n=18)\end{array}$ & $\begin{array}{l}\text { Exact } \\
\text { p value }\end{array}$ \\
\hline Male & 14 & 6 & 8 & 0.024 \\
Female & 10 & 0 & 10 & \\
\hline
\end{tabular}

(exact $\mathrm{p}$ value $=0.00004, \chi^{2}=20.3$, relative risk $=6.3$ ). When the exact $\mathrm{p}$ value was corrected for the number of HLA antigens tested (53), this HLA-B51 association remained highly significant (corrected exact $\mathrm{p}$ value $=0.002$ ). The HLA-B51 antigen was found in six out of 24 patients (25\%) compared with none of the 96 controls.

An increased frequency was observed for HLA-B7 (exact $\mathrm{p}$ value $=0.008$ ) in the BD group compared with the control group. We also observed an increased frequency of two HLA class II antigens, HLA-DR6 (exact $p$ value $=0.007$, relative risk $=5.7$ ) and HLADR2 (exact $\mathrm{p}$ value $=0.041)$, in patients with Behçet's disease compared with controls. However, after correction of the exact $p$ values for the number of antigens tested (53), the observed differences for HLA-B7, HLA-DR6, and HLA-DR2 did not reach a level of significance.

Sex differences in HLA-B51 status are outlined in Table 2. Of patients with the HLA-B51 antigen, all six were male (exact $p$ value $=0.024$ ) with a male sex:HLA-B51 association achieving probable significance. All 10 female patients were negative for the HLA-B51 antigen. Age at first manifestation and at diagnosis of Behçet's disease with respect to HLA-B51 status is given in Table 3. No difference was found within the BD group for age at first manifestation (exact $\mathrm{p}$ value $=$ 0.160 ) between patients who were HLA-B51 antigen positive (mean age 25.5 years (SD 8.12)) and those who were HLA-B51 negative (mean age 19.2 years (7.28)). Mean age at diagnosis of BD was 28.5 years (8.26) in the HLA-B51 positive group compared with 30.0

Table 3 HLA-B51 status and age in Irish Behçet's disease

\begin{tabular}{|c|c|c|c|}
\hline & \multicolumn{2}{|l|}{ HLA-B51 status } & \multirow[b]{3}{*}{ Exact p value } \\
\hline & B51 positive $(n=6)$ & B51 negative $(n=18)$ & \\
\hline & Mean age (years) (SD) & Mean age (years) $(S D)$ & \\
\hline Age at first manifestation & $25.5(8.12)$ & $19.2(7.28)$ & 0.160 \\
\hline
\end{tabular}

Table 4 HLA-B51 status and clinical characteristics in Irish Behçet's disease

\begin{tabular}{|c|c|c|c|c|}
\hline & \multirow[b]{2}{*}{ Total } & \multicolumn{2}{|c|}{$H L A-B 51$ status } & \multirow[b]{2}{*}{ Exact p value } \\
\hline & & B51 positive & B51 negative & \\
\hline \multicolumn{5}{|c|}{ Eye involvement } \\
\hline+ & 19 & 14 & 5 & \multirow{2}{*}{1.000} \\
\hline- & 5 & 4 & 1 & \\
\hline \multicolumn{5}{|c|}{ CsA therapy } \\
\hline+ & 7 & 5 & 2 & \multirow[t]{2}{*}{1.000} \\
\hline - & 17 & 13 & 4 & \\
\hline \multicolumn{5}{|c|}{ Visual acuity $<6 / 60^{\star}$} \\
\hline+ & 6 & 4 & 2 & \multirow[t]{2}{*}{1.000} \\
\hline - & 13 & 10 & 3 & \\
\hline
\end{tabular}

ॠVisual acuity of patients with eye involvement $(n=19)$. years (5.73) in the HLA-B51 negative group with no significant difference (exact $\mathrm{p}$ value $=$ 0.867).

Nineteen patients $(79.2 \%)$ in the BD group had eye involvement with five possessing the HLA-B51 antigen while 14 patients did not. There was no association between HLA-B51 positivity and eye involvement (exact $\mathrm{p}$ value $=$ 1.00). No association was seen between the HLA-B51 antigen and requirement for systemic cyclosporin A therapy (exact $\mathrm{p}$ value $=$ 1.00 ) or visual acuity worse than $6 / 60$ in patients with eye involvement (exact $\mathrm{p}$ value $=$ 1.00 , Table 4). Of six patients with a visual acuity worse than $6 / 60$ in an affected eye, only two possessed the HLA-B51 antigen.

\section{Discussion}

The most significant finding in our study is a highly significant association between HLAB51 and Behçet's disease (corrected exact p value $=0.002$ ) in the Republic of Ireland which has an ethnically homogeneous white population. Mizuki et $a l^{5}$ has suggested that the same HLA-B51 association exists worldwide and this has been confirmed in many different ethnic groups, but mostly from the Far East and Mediterranean countries. ${ }^{4-13}$ This HLA-B51 association is unclear, however, in white patients from north western Europe and the USA.

Previous older studies from Britain ${ }^{18} 19$ and the $\mathrm{USA}^{1620}$ in the 1970 s do not show any HLA-B5 association. O'Duffy et al found no HLA association in 26 US patients ${ }^{16}$ and more recently stated in an editorial in the New England fournal of Medicine ${ }^{17}$ that no HLA association existed in either US or British patients. In the largest American series of BD patients to date ( 35 patients), Foster et al could not find a HLA-B51 association. ${ }^{22}$ Previous North American studies in whites have been, however, from ethnically diverse groups. ${ }^{16223}$ Lehner et al ${ }^{19}$ typed 52 white British patients and found no HLA-B5 association, verifying the results of a previous British study, ${ }^{18}$ though there was an association (uncorrected $\mathrm{p}=$ 0.002) with the 'ocular type' using an unusual classification system. The only previous Irish study on Behçet's disease found no HLA-B5 association in a small group of six typed patients. ${ }^{25}$ The results of these older studies are difficult to interpret as they were performed before the HLA-B5 complex was differentiated into its subantigens, HLA-B51, B52, and B53. In addition, different and older diagnostic criteria for diagnosis were used before the advent of the ISG criteria, therefore making comparison different. A more recent study in 14 ethnically homogeneous Scottish patients using the ISG criteria found no HLA-B5 proband association. ${ }^{26}$ However, the HLA-B5 antigen was not subtyped and while only $13 \%$ Scottish BD patients were HLA-B5 positive the authors did not report the HLA-B5 frequency in normal Scottish controls precluding statistical comparison.

In Germany, however, two studies reported an increased frequency of HLA-B5 in BD patients of $23 \%$ (compared with $14 \%$ of 
controls) $)^{27}$ and $67 \%^{28}$ using the ISG criteria. Comparison was made of German BD patients with Mediterranean patients and not with normal controls in the latter study. ${ }^{28}$ Zouboulis et $a l^{27}$ reported a statistically significant HLA-B5 association $(\mathrm{p}<0.05)$ with a low relative risk of 2.6 but did not correct $\mathrm{p}$ values to avoid a type I error ${ }^{24}$ which would not produce a significant difference between groups.

Both these studies had inappropriate statistical analyses, ${ }^{27}{ }^{28}$ comparing a small number of patients with a very much greater number of controls. ${ }^{29}$ Associations between HLA and diseases should be investigated with an equal number of patients and controls for a near optimal estimation of relative risk. ${ }^{30}$ However, the optimal sampling ratio in our group for a precise estimate of relative risk is a control group four times the number of patients, ${ }^{30}$ and this increases the power of the test to an optimal level beyond which diminishing power gains will be achieved. ${ }^{31}$

Support for an immunogenetic HLA-B51 predisposition came from Villaneuva et $a l^{32}$ in a Mediterranean family from the south of Spain. They described three sisters with BD (ISG criteria) out of six siblings, with all affected siblings possessing identical HLA haplotypes and all siblings possessing the HLA-B51 antigen.

Behçet's disease is relatively rare in north western Europe and the significance of studies on smaller series of European patients is particularly difficult to interpret. ${ }^{3}$ There are no prevalence data for $\mathrm{BD}$ in Ireland and our study is the largest Irish series to date. Assuming a roughly similar prevalence to Yorkshire ${ }^{18}$ of 0.6/100 000 population, one would expect there to be 21 or 22 patients with BD in the Republic of Ireland from current census data. ${ }^{33}$ Our study on 24 patients has probably recruited the vast majority of $\mathrm{BD}$ patients in the Republic of Ireland. Despite HLA-B51 being present in only $25 \%$ of Irish BD patients, when compared with B51 positivity in none of the controls, this produces a relative risk of 6.3. While the proportion of HLA-B51 in BD patients is much higher in $\operatorname{Japan}^{45}$ and Turkey, ${ }^{34}{ }^{35} 57 \%$ and $82 \%$ with relative risks of 7.9 and 14 respectively, the high relative risk in our study is similar. While our study reports a highly significant HLA-B51 association and strong immunogenetic predisposition for $\mathrm{BD}$ in those who possess the HLA-B51 antigen, $75 \%$ of Irish BD patients were HLA-B51 negative and indicates a multifactorial pathogenesis for BD. This is supported by the Spanish familial study, ${ }^{32}$ and another Japanese family with $B D,{ }^{36}$ where all affected and unaffected siblings possessed the HLA-B51 antigen. The B51 antigen has been recently subdivided into three alleles, HLA-B ${ }^{\star} 5101$, HLA-B ${ }^{\star} 5102$, and HLA-B ${ }^{\star} 5103$, with all $B 51$ positive patients in a Japanese study ${ }^{37}$ possessing HLA-B ${ }^{\star} 5101$. This allele differs from the other two by a single amino acid substitution in each case, and this would merit further study in our B51 positive Irish patients.

In support of previous studies of $\mathrm{BD},{ }^{19}{ }^{27}$ we have found a significant association of HLA-
B51 positivity with male sex (exact $\mathrm{p}$ value $=$ $0.024)$. However, with respect to other clinical associations, such as age at first presentation/ diagnosis, eye involvement, and severity of ocular disease/poor visual acuity, we found no HLA-B51 association, in common with many other studies from the Far East and Europe. ${ }^{27}{ }^{38-41}$ Wechsler et al have questioned whether the HLA-B51 antigen is relevant for the severity of Behçet's disease. ${ }^{42}$ We would suggest that it is not, and we attribute particular importance to the distinct lack of HLA-B51 association with severity of ocular disease found in this study. Two recent studies from Japan $^{39}$ and Korea ${ }^{41}$ also could not find a HLAB51 association with poor visual prognosis.

In conclusion, our study found a highly significant HLA-B51 association with BD in Ireland, with a high relative risk. A positive HLAB51:male sex association and no association with visual prognosis in Behçet's disease was confirmed. This study supports a HLA-B51 immunogenetic predisposition in an ethnically homogeneous white population in north western Europe, far from the Silk Route.

Presented in part at the XIXth meeting of the Club Jules Gonin, Versailles, France, 1994.

The authors wish to gratefully acknowledge the helpful comments of $\mathrm{Mr}$ Andrew Dick, Department of Ophthalmology, Aberdeen, the statistical advice of Dr Tony Holohan, Department of Public Health Medicine, Eastern Health Board, and Dr Mary Codd, Department of Epidemiology, Mater Misericor-
diae Hospital, Dublin.

1 Nussenblatt RB. Behçet's disease. In: Nussenblatt RB, Whitcup SM, Palestine AG, eds. Uveitis: fundamentals and clinical practice. 2nd ed. St Louis: Mosby, 1996:334-53.

2 Inomata H, Kohno T, Rao NA, Ryan SJ. Vasculitis and intraocular neovascularisation in Behçet's disease: histopathology of the early and advanced late stages. In: Dernouhamps JP, Verougstraete C, Caspers-Velu L, Tassignon MJ, eds. Recent advances in uveitis: proceedings of the third international symposium on uveitis, Brussels, Belgium, May 24-27,1992. Amsterdam: Kugler, 1993:349-55.

3 Dinning WJ. Behçet's syndrome. In: Gold DH, Weingeist TA, eds. The eye in systemic disease. Philadelphia: J B Lippincott, 1990:279-81.

4 Ohno S, Aoki K, Sugiura S, Nakayama E, Itakura K, Aizawa M. HL-A5 and Behçet's disease. Lancet 1973;2:1383.

5 Mizuki N, Ohno S, Tanaka H, Sugimura K, Seki T, Mizuki J, et al. Tissue antigens 1992;40:22-30.

6 Mizuki N, Inoko H, Mizuki N, Tanaka H, Kera J, Tsuji K, et al. Human leukocyte antigen serologic and DNA typing of
. Behçet's disease and its primary association with B51. Behçet's disease and its primary association
Invest Ophthalmol Vis Sci 1992;33:3332-40.

7 Lee S, Koh YJ, Kim DH, Bang D, Nam IW, Lee KH, et al. A study of HLA antigens in Behçet's syndrome. Yonsei Med f 1988;29:259.

8 Chung YM, Tsai ST, Liao F, Liu JH. A genetic study of Behçet's disease in Taiwanese Chinese. Tissue Antigens 1987;30:68.

9 Ohno S. Immunogenetic studies on ocular diseases. In: Blodi F, et al, eds. Acta XXV Concilium Ophthalmologicum. Amsterdam: Kluger \& Ghedini, 1986:144-54.

10 Chajek-Shaul T, Pisanty S, Knobler H, Matzner Y, Glick M, Ron N, et al. HLA-B51 may serve as an immunogenetic marker for a subgroup of patients with Behçet's syndrome. Am F Med 1987;83:666.

11 Arber N, Klein T, Meiner Z, Pras E, Weinberger A. Close association of HLA-B51 and B52 in Israeli patients with association of HLA-B51 and B52 in Israeli patients

12 Yazici H, Tuzun Y, Pazarli H, Yalcin B, Yurdakul S, Muftuoglu A. The combined use of HLA-B5 and the pathergy test as diagnostic markers of Behçet's disease in Turkey. F Rheumatol 1980;7:206.

13 Zervas J, Vayopoulos G, Sakellaropoulos N, Kaklamanis PH, Fessan PH. HLA antigens and adamantiades-Behçet's disease (A-BD) in Greeks. Clin Exp Rheumatol 1988;6:277.

14 Ohno S, Ohguchi M, Hirose S, Matsuda H, Wakisaka A, Aizawa M. Close association of HLA-Bw51 with Behçet's disease. Arch Ophthalmol 1982;100:1445.

15 Mizushima Y. Recent research into Behçet's disease in Japan. Int $\mathcal{F}$ Tissue React 1988;10:59.

16 O'Duffy JD, Taswell HF, Elveback LR. HL-A antigens in Behçet's disease. 7 Rheum 1974;3:1

17 O'Duffy JD. Behçet's syndrome. N Engl f Med 1990;322: 326-8.

18 Chamberlain MA. Behçet's syndrome in 32 patients in Yorkshire. Ann Rheum Dis 1977;36:491. 
19 Lehner T, Batchelor JR, Challacombe SJ, Kennedy L. An immunogenetic basis for the tissue involvement in Behçet's immunogenetic basis for the tissue involve

20 Ohno S, Char DH, Kimura SJ, O'Connor GR. Studies on HLA antigens in American patients with Behçet's disease. fpn $\mathcal{F}$ Ophthalmol 1978;22:58-61.

21 Moore SB, O'Duffy JD. Lack of association between Behçet's disease and major histocompatibility complex II antigens in an ethnically diverse North American Caucasoid patient group. F Rheumatol Canada 1986;13:771-3.

22 Foster CS, Baer J. Behçet's disease in America: ocular manifestations and response to treatment. In: Dernouchamps JP, Verougstraete C, Caspers-Velu, Tassignon MJ, eds. Recent advances in uveitis: proceedings of the third international symposium on uveitis, Brussels, Belgium, May 24-27, 1992. Amsterdam: Kugler, 1993:185-9.

23 International Study Group for Behçet's Disease. Criteria for diagnosis of Behçet's disease. Lancet 1990;335:1078-80.

24 Meenken C, Rothova A, de Waal LP, van der Horst AR, Mesman BJ, Kijlstra A. HLA typing in congenital toxoplasMesman BJ, Kijlstra A. HLA typing in cong
mosis. Br F Ophthalmol 1995;79:494-7.

25 Collum LMT, Mullaney J, Bowell R. Current concepts of Behçet's disease. Trans Ophthalmol Soc UK 1981;101:4228.

26 Jankowski J, Crombie I, Jankowski R. Behçet's syndrome in Scotland. Postgrad Med F 1992;68:566-70.

27 Zouboulis CC, Buttner P, Djawari D, Kirch W, Keitel W, Garbe C, et al. HLA-muster bei morbus AdamantiadesBehcet in Deutschland. Hautarzt 1993;44:81-5.

28 Zierhut M, Saal J, Pleyer U, Kotter I, Durk H, Fierlbleck G. Behçet's disease: epidemiology and eye manifestations in German and Mediterranean patients. Ger f Ophthalmol 1995;4:246-51.

29 Mizuki N, Inoko $\mathrm{H}$, Ohno $\mathrm{S}$. Role of HLA and $\mathrm{T}$ lymphocytes in the immune response. Ocular Immunol Inflamm 1994;2:57-91.

30 Walter SD. Determination of significant relative risks and optimal sampling procedures in prospective and retrospec- tive comparative studies of various sizes. Am $\mathcal{f}$ Epidemiol 1977;105:387-97

31 Gail M, Williams R, Byar DP, Brown C. How many controls? F Chron Dis 1976;29:723-31

32 Villaneuva JL, Gonzalez-Dominguez J, Gonzalez-Fernandez R, Prada JL, Pena J, Solana R. HLA antigen familial study in complete Behçet's syndrome affecting three sisters. Ann Rheum Dis 1993;52:155-7.

33 Preliminary report of the 1996 census, Central Statistics Office, Dublin, Republic of Ireland.

34 Tirawa JL, Terasaki PI. HLA and disease associations. New York: Springer Verlag, 1985.

35 Yurkadul S, Gunaydin I, Tuzun Y, Tankurt N, Pazarli H, Ozyazgan Y, et al. The prevalence of Behçet's syndrome in a rural area in northern Turkey. F Rheumatol 1988;15:8202.

36 Hayasaka S, Kurome H, Noda S. HLA antigens in a Japanese family with Behçet's disease. Graefes Arch Clin Exp Ophthalmol 1994;232:589-90.

37 Mizuki N, Inoko H, Ando H, Nakamura S, Kashiwase K, Akaza T, et al. Behcet's disease associated with one of the HL A-B51 subantigens, HLA-B ${ }^{\star 5101 . ~ A m ~} \mathcal{f}$ Ophthalmol 1993;116:406-9.

38 Soylu M, Ersoz TR, Erken E. The association between HLA $\mathrm{B} 5$ and ocular involvement in Behcet's disease in southern Turkey. Acta Ophthalmol 1992;70:786-9.

39 Sakamoto M, Akazawa K, Nishioka Y, Sanui H, Inomata H, Nose Y. Prognostic factors of vision in patients with Behçet's disease. Ophthalmology 1995;102:317-21.

40 Cocherau-Massin I, Wechsler B, Le Hoang P, Le Thi Huong Du, Girard B, Rousselie F, et al. Ocular prognosis in Behçet's disease. F Fr Ophtalmol 1992;15:343-7.

$41 \mathrm{Kim}$ MS, Kim JH. Prognostic comparison of Behcet's disease with or without HLA-Bw51 antigen. Korean $\mathcal{F} O p h-$ thalmol 1989;3:85-9.

42 Wechsler B, Piette JC. Behçet's disease. BMf 1992; 304:1199-200. 